\title{
Engagement of Nepalese High-School Students in Cancer Awareness Using a Photovoice Based on the Health Belief Model
}

\author{
Kritika Poudel ${ }^{1,2}$ (D) and Naomi Sumi ${ }^{2, *(D)}$ \\ 1 Center for Environmental and Health Sciences, Hokkaido University, North 12, West 7, \\ Sapporo 060-0812, Japan; kpoudel@hs.hokudai.ac.jp \\ 2 Faculty of Health Sciences, Hokkaido University, North 12, West 5, Sapporo 060-0812, Japan \\ * Correspondence: nsumi@hs.hokudai.ac.jp
}

check for

updates

Citation: Poudel, K.; Sumi, N.

Engagement of Nepalese High-School

Students in Cancer Awareness Using

a Photovoice Based on the Health

Belief Model. Healthcare 2021, 9, 1283.

https: / / doi.org/10.3390/

healthcare 9101283

Academic Editors: José

Carmelo Adsuar Sala and Maya

K. Gislason

Received: 23 August 2021

Accepted: 26 September 2021

Published: 28 September 2021

Publisher's Note: MDPI stays neutral with regard to jurisdictional claims in published maps and institutional affiliations.

Copyright: (c) 2021 by the authors. Licensee MDPI, Basel, Switzerland. This article is an open access article distributed under the terms and conditions of the Creative Commons Attribution (CC BY) license (https:/ / creativecommons.org/licenses/by/ $4.0 /)$.

\begin{abstract}
Delivering cancer education is one of the strategies for implementing health promotion and disease prevention programs. Moreover, cancer education can help people understand the risks related to specific behaviors that can trigger cancer during later life stages. This study examines the cancer perception of high school students (median age: 14 years) using a photovoice based on the health belief model. Students were requested to take photographs to answer the framework question: "How is cancer present in your surrounding?" A theoretical thematic analysis was conducted to develop codes, and the narratives completed by the participants on the SHOWED checklist were used to create contextualization. With the use of the health belief model, the following factors were determined: risk factors and environmental pollution (perceived susceptibility), symptoms (perceived severity), prevention and screening (benefits), ignorance and poverty, and ineffective laws and regulations (perceived barriers). Linked to these themes, students' narration demonstrated the risk of developing cancer if the same environment and inadequate regulations persisted. This study highlights the need to incorporate the participation of adolescents in the design, implementation, and monitoring of several community issues to help address several unanswered questions.
\end{abstract}

Keywords: cancer perception; high school students; adolescents; photovoice method; Nepal

\section{Introduction}

Adolescent health is described as a different range of approaches for the prevention, detection, or treatment associated with young people's health and well-being [1]. The comprehensive adolescent health package includes promoting mental health and wellbeing, a safe environment, improving access to nutritious and healthy food, mitigating the negative consequences associated with substance abuse, promoting physical activity, and improving healthcare-seeking behaviours in communities. A multidimensional approach is required to safeguard adolescent health, such as through families to protect and nurture, schools to promote healthy development, healthcare that is responsive to the needs of adolescents, a safe transport system, and laws to protect adolescents' rights [2].

Approximately $23.6 \%$ of Nepal's population comprises adolescents aged 10-19 years [3]. During adolescence, young people acquire new habits and behaviors. Various risk factors, such as alcohol and tobacco use, inadequate physical activity, unprotected sexual habits, or violence can threaten their current and future health as they reach adulthood [4]. Although most instances of adolescent morbidity and mortality are preventable, adolescents face several barriers in accessing health information and services [5]. Furthermore, there is an alarming issue of sexual and reproductive health concerns among adolescents in Nepal [6]. Although many studies have been conducted to understand issues related to sexual and reproductive health, substance abuse, and school-based health programs $[7,8]$, there is limited evidence to address cancer awareness in Nepal. Increasing cancer awareness among 
adolescents can supplement their knowledge and aid in recognizing cancer symptoms early and search for timely medical help during adolescence and adulthood [9]. Providing health education is one of the strategies for implementing health promotion and disease prevention programs. Cancer education can help adolescents understand the risks related to specific behaviors that can trigger the origin of cancer during later life stages. Repetitive and streamlined education programs focused on diseases may further help students understand the association between specific habits and cancer. However, these habits do not persist for an extended period, thereby rendering this method ineffective $[10,11]$. Furthermore, cancer education programs have been proven to be effective when adolescents, peer groups, and families easily share opinions [9,10,12-14].

The health belief model (HBM) was developed during the early 1950s and remains one of the popular models used in health education programs. HBM includes four major subscales-perceived susceptibility, severity, benefits, and barriers. Several factors determine the likelihood that an individual will act to prevent or detect disease: perceived susceptibility to the health condition, perceived severity of the health threat, perceived benefits of performing the health behavior, and perceived barriers to performing this behavior $[15,16]$. In addition, there are two other subscales: cue to action and self-efficacy. In this study, we used the four major subscales to understand the cancer perceptions of participants through a photovoice.

A photovoice is the process of used to identify, represent, and enhance a community through photographic methods. Previously known as photo novella, the photovoice approach has been used for various community-based participatory research (CBPR) projects, primarily to enable people to record and reflect on different aspects of the community, promote critical knowledge through discussions of photographs taken, and ensure that their concerns are addressed by policymakers [17]. Photovoices allow participants to actively engage with researchers in the research process and enable the exchange of opinions and experiences [18]. Various studies have used photovoices as a research methodology to explore the thoughts of participants and empower local assessment $[19,20]$. Additionally, photovoices are used as a pedagogical tool to examine the learning process of the students as well as to introduce qualitative research methods to community members. These studies helped to record the voices of individuals and their visions for their lives and communities.

Although some studies have used a photovoice as a teaching tool in different classrooms [21-23], to date, a photovoice has not been utilized in cancer education research. The photovoice method encourages participants to engage in the research process and provides access to subjective experiences that are difficult to address from the outside; thus, we aimed to understand student perceptions regarding cancer by using a photovoice among school students.

\section{Materials and Methods}

This qualitative study was conducted in different schools in Lalitpur metropolitan city, Nepal. Convenience sampling was used to select schools for data collection. Permission to conduct this study was obtained from the school principal, teachers, parents, and students. High school students in the same grade were recruited as study participants.

\subsection{Photovoice Research Method}

Different exercises were conducted to ensure students were familiar with the photovoice.

1. Training: The researchers introduced the aim and the photovoice process to the participants. A 90-min training session was provided regarding the photovoice and its purpose in the current study, camera usage, and photography ethics. Participants were requested to obtain informed consent when taking photographs of people.

2. Data collection: The SHOWED checklist was provided to participants. The researchers explained to participants how they could present their opinions about the photos based on the SHOWED checklist [24]. 
The questions in the SHOWED checklist are as follows:

1. What do you see here?

2. What is really happening here?

3. How does this relate to our lives?

4. Why does this problem or this strength exist?

5. What can we do about this?

Participants were divided into a group of six students. The framing question "How is cancer present in your surrounding?" was posed to them. Each group was given three days to take photos and answer the questions. They were requested to select photos that they perceived as the most meaningful as well as those that represented their thoughts.

\subsection{Group Discussion by Theme}

Each student discussed their best representative photos with their respective groups. Following this, the researcher facilitated a comprehensive discussion. Students were requested to relate the narration of each photo to their groups. Based on the discussion, groups were requested to develop a poster. Each group was allocated five minutes to describe their posters in front of all the groups.

Data Analysis

After the photovoice session, a theoretical thematic analysis was conducted to develop the codes. The narratives completed by the participants on the SHOWED checklist $[17,25]$ were used to develop contextualization. The codes were generated and modified to create the themes. These themes had to directly address the framing question: "How is cancer present in your surrounding?". Rather than the photographs, the narration was analyzed to develop themes. The researchers maintained neutrality to ensure the situations were not intentionally influenced or manipulated.

\section{Results}

\subsection{General Characteristics of Participants}

A total of 152 students participated in this study through convenience sampling. The median age of the participants was 14 years, and approximately $53.9 \%(\mathrm{~N}=82)$ were female. A total of $30.3 \%(\mathrm{~N}=46)$ of participants had talked about or discussed cancer with their friends/families, and around $79.6 \%(\mathrm{~N}=121)$ of participants had considered cancer talk as an important factor in cancer education. Figure 1 presents the photographs selected by the participants. The narratives are presented in Table 1 . Based on the narration, the photographs were divided into different themes based on the HBM. Although not directly associated, participants also emphasized environmental factors, such as air pollution, sewage, and improper waste management as risk factors for various diseases. 



Figure 1. Photovoice photographs (numbered by health belief subscales). 
Table 1. Selected summary of photovoice narratives by participants (please refer to Figure 1).

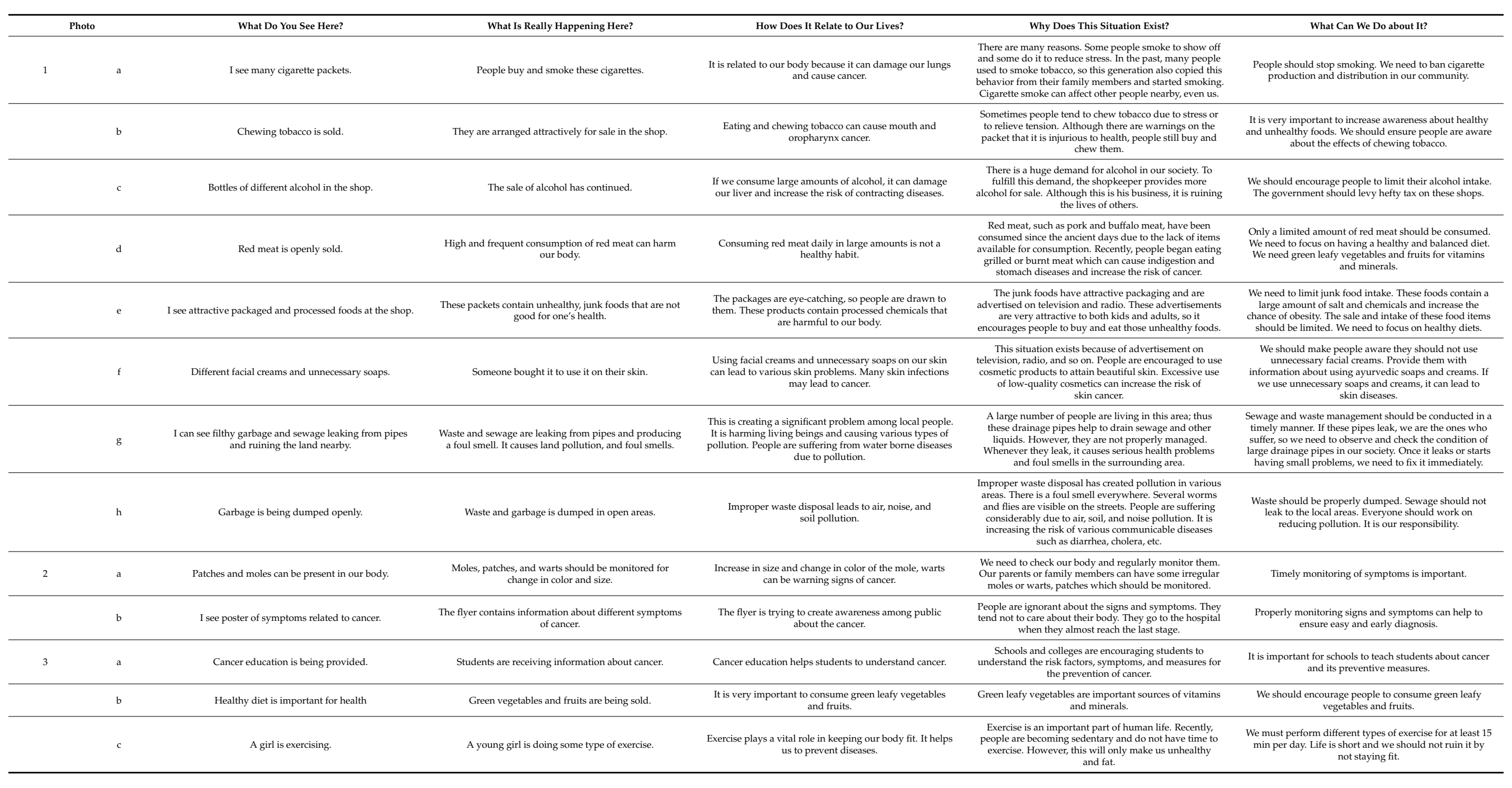


Table 1. Cont

\begin{tabular}{|c|c|c|c|c|c|c|}
\hline \multicolumn{2}{|r|}{ Photo } & What Do You See Here? & What Is Really Happening Here? & How Does It Relate to Our Lives? & Why Does This Situation Exist? & What Can We Do about It? \\
\hline & d & I see books. & Books are the source of education. & $\begin{array}{l}\text { We go to school to learn new things every day. Books } \\
\text { provide considerable information about diseases } \\
\text { and health. }\end{array}$ & $\begin{array}{l}\text { We need to develop the habit of studying and reading } \\
\text { more books. Newspapers and posters a also another } \\
\text { source of information. They provide the latest } \\
\text { information about diseases, drugs, discovery, } \\
\text { and challenges. }\end{array}$ & $\begin{array}{l}\text { Everyone needs to know about and read books. We can } \\
\text { teach our family by sharing information from books. } \\
\text { Books are an important part of a student's life. }\end{array}$ \\
\hline & $\mathrm{f}$ & $\begin{array}{l}\text { I see someone is checking their blood pressure at the } \\
\text { health post nearby. }\end{array}$ & $\begin{array}{l}\text { A person is checking their blood pressure and is eager to } \\
\text { know their blood pressure level. }\end{array}$ & $\begin{array}{l}\text { We must have a normal blood pressure range. High or } \\
\text { low blood pressure is risky to health. }\end{array}$ & $\begin{array}{l}\text { This person wants to know their blood pressure, thus, he } \\
\text { is at a regular check-up. Peeple should have regular } \\
\text { checkups to monitor their weight, blood pressure, and } \\
\text { sugar level. }\end{array}$ & $\begin{array}{l}\text { This is preventive measures. We should check our blood } \\
\text { pressurut timely. Also, we should maintain our salt titake } \\
\text { Regular checkup helps to prevent diseases. }\end{array}$ \\
\hline & $\mathrm{g}$ & I see hospital posters. & We should go to the hospital without delay. & $\begin{array}{l}\text { Many people do not go for treatment in the early stage } \\
\text { even when hospitals are nearby. }\end{array}$ & $\begin{array}{l}\text { Hospitals are there for people. For timely diagnosis and } \\
\text { specialized treaatment, people need to go to hospital early. } \\
\text { They should not depend on neighbors talks and } \\
\text { tradititional beliefs. }\end{array}$ & $\begin{array}{l}\text { Many people seek advice from family, neighbors and } \\
\text { follow their advice even if they are seriously ill. We must } \\
\text { educate people about going to hospital on time and not } \\
\text { delaying their treantment. Health is wealth. }\end{array}$ \\
\hline \multirow[t]{5}{*}{4} & a & A mother feeding her child. & A mother is buying street foods and feeding her child. & $\begin{array}{l}\text { Junk foods are cheaper and other foods are expensive. } \\
\text { Ignorant, illiterate, and poor people do not have money } \\
\text { to eat healthy foods. }\end{array}$ & 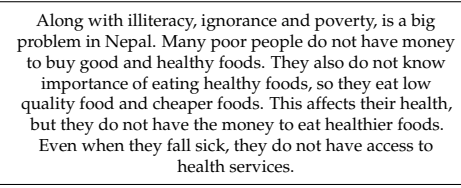 & $\begin{array}{l}\text { Cancer awareness programs should be conducted. The } \\
\text { government should reduce the prices of vegetableses, } \\
\text { education, and medical treatment so that everyone can } \\
\text { access to them. Is the screening test for cancer free? }\end{array}$ \\
\hline & $\mathrm{b}$ & There is an advertisement of beer in the photo. & Some beer companies are advertising their beer. & $\begin{array}{l}\text { It influences many people to buy and consume beer. } \\
\text { Alcohol affects our health badly. }\end{array}$ & $\begin{array}{l}\text { Advertisements attract young and old people to buy beer. } \\
\text { These advertisements are everywhere in the market. } \\
\text { Many students hid and drink alcohol because their } \\
\text { advertisements are attractive. }\end{array}$ & $\begin{array}{l}\text { Why is the government showing these advertisements on } \\
\text { the television, radio, boards? Can we ask the governmen } \\
\text { to ban the sale of alcohol? }\end{array}$ \\
\hline & c & The shop has variety of alcohol. & Everyone can go and buy alcohol. & $\begin{array}{l}\text { We can buy alcohol from the shop if we say it is an order } \\
\text { from our parents. }\end{array}$ & $\begin{array}{l}\text { There are no strict laws or rules for buying alcohol. } \\
\text { Anyone can go and buy it. Although we cannot drink } \\
\text { alcohol because we are under } 18 \text { years of age, we can } \\
\text { hide and do whatever we want. }\end{array}$ & $\begin{array}{l}\text { Shopkeepers should not allow children to buy alcohol, } \\
\text { even if it if sor their parents' chonsumption. They alaso } \\
\text { should not allow children to buy cigarettes for } \\
\text { their parents. }\end{array}$ \\
\hline & $\mathrm{d}$ & I see a non-smoking poster. & $\begin{array}{l}\text { The government has put non-smoking posters in some } \\
\text { areas. }\end{array}$ & $\begin{array}{c}\text { This poster discourages people from smoking in these } \\
\text { areas. }\end{array}$ & $\begin{array}{l}\text { Although these posters are there, people do not care and } \\
\text { still smoke in front of the poster. }\end{array}$ & $\begin{array}{l}\text { Giving punishments and penalties to those who do not } \\
\text { follow the rule. }\end{array}$ \\
\hline & e & I see a medical pharmacy. & Lots of medicines are available for sale. & $\begin{array}{l}\text { After treatment, many people need to take medicines, but } \\
\text { they are expensive. }\end{array}$ & $\begin{array}{l}\text { When people are unhealthy, they do not go to hospital on } \\
\text { time, thus, delaying treat,ent. Also, the medicines and } \\
\text { treatments for cancera rare expensive. Many people cannot } \\
\text { afford these medicines so they do not go to the hospital } \\
\text { unless they are very sick. Also, people tan buy many } \\
\text { medicines directly without a doctor's prescription. }\end{array}$ & $\begin{array}{l}\text { The government should decrease the price of expensive } \\
\text { medicines. The pharmacist should not give medicines to } \\
\text { people without a prescription. }\end{array}$ \\
\hline
\end{tabular}




\subsection{Defining Cancer Perception: How Is Cancer Present in Your Surrounding?}

\subsubsection{Cancer and Susceptibility}

Participants described different risk factors that can increase the susceptibility of cancer risk, thereby creating the sub-theme "Risk factors" (see Figure 1 [1a-f]; Table 1 [1a-f]) and environmental pollution (see Figure $1[1 \mathrm{~g}-\mathrm{h}]$; Table $1[1 \mathrm{~g}-\mathrm{h}]$ ). Participants discussed different risk factors such as tobacco (smoking and chewing), alcohol consumption, excessive consumption of red meat, high intake of processed and junk foods, and use of different cosmetics that can increase the susceptibility of cancer. Students also highlighted garbage and open sewage pipes, which can increase the risk of waterborne diseases in their communities. Although Figure $1[1 \mathrm{~g}-\mathrm{h}]$ is not related to cancer susceptibility, students assumed that these environmental pollutants could contaminate water, soil, and air, thereby leading to unhygienic living areas that could trigger various diseases.

\subsubsection{Cancer and Severity}

Participants underlined different potential symptoms of cancer, thus creating the sub-theme "Symptoms" (see Figure 1 [2a-b]; Table 1 [2a-b]). Changes in skin color, size of warts and moles, and blood noted while coughing were discussed. During the narration, participants focused on the severity of cancer and the importance of properly monitoring symptoms during the early diagnosis of cancer.

\subsubsection{Cancer and Benefits}

Two sub-themes, "Prevention" and "Screening," were developed based on the narration of participants. The sub-theme "Prevention" (see Figure 1 [3a-e]; Table 1 [3a-e]) highlighted the importance of cancer education, healthy diet, exercise, reading books, and consumption of organic foods. Another sub-theme, "Screening," focused on regular check-ups and hospital access for treatments. Participants were aware of the different services being provided by the hospitals and their role in screening for diseases.

\subsubsection{Cancer and Barriers}

Participants emphasized different aspects of their community that can serve as a barrier to cancer awareness and treatment. Two sub-themes were developed based on the narration: "Ignorance and Poverty" and "Ineffective law and regulations." Under the sub-theme "Ignorance and Poverty" (see Figure 1 [4a]; Table 1 [4a]), participants noted the medical and treatment services being expensive, such that all citizens could not access them. They also questioned whether cancer screening tests are conducted free-of-charge. The sub-theme "Ineffective laws and regulations" (see Figure 1 [4b-e]; Table 1 [4b-e]) highlighted the ineffective laws related to buying, selling and hoarding alcohol, as well as the availability of medicines without prescription. Participants criticized the actions of the government with regards to regulating advertisements for tobacco and alcohol on social media.

\subsection{Cancer Perception and Health Belief Model}

Figure 2 presents a summary of the thematic analysis through the HBM. Participants' narratives and codes linked the four subscales of the HBM. Figure 2 was developed based on the themes derived from the SHOWED checklist responses of participants. Participants were susceptible to various risk factors that can contribute to developing cancer. They perceived symptoms as the severity of the diseases and perceived prevention and screening as the benefits of cancer treatment. Ineffective law and regulations and poverty were considered barriers to cancer prevention. (INSERT FIG 2). 


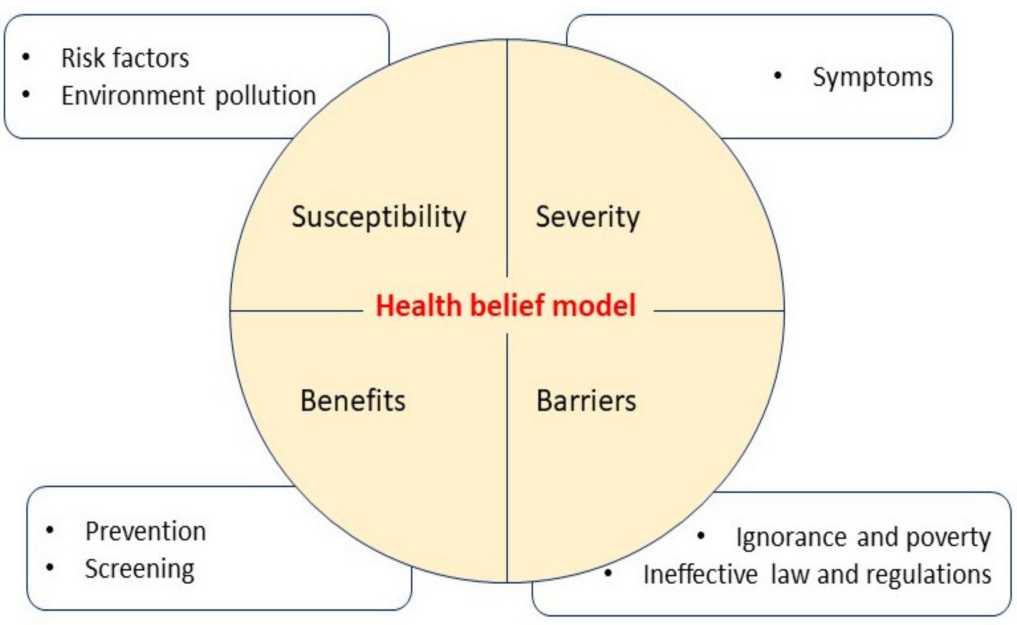

Figure 2. Defining the cancer perception via health belief model.

\section{Discussion}

The purpose of this study was to understand the perceptions of high school students regarding cancer by using the photovoice process. We examined how adolescent students perceived cancer in their community in terms of the risk factors, preventive measures, or health barriers. This study also included cancer communication among friends and discussions regarding cancer while getting involved in the photovoice process. These students were adolescents and thus understood the importance of peer influence among those in this age group; therefore, we formed groups to conduct the photovoice. Several studies have revealed the role of peers in directly and indirectly shaping health behaviors, well-being, and perceptions about school [26]. A study showed that peers play an important role in influencing risk or protective behaviors [27]. Our previous study also supported the idea of peer group discussion in encouraging active learning and problem-solving through more sustainable methods [10].

In the current world, adolescents are actively engaged in different types of digital media. Social media can provide an opportunity for adolescent education, self-expression, creativity, and entertainment [2]. Photovoices have been used as a research tool among adolescents in various studies. Studies have used photovoices to promote social action and civic participation among adolescents to improve school conditions [28,29]. In this study, we used a photovoice as a tool to understand the opinions of students regarding cancer. Participants discussed various risk factors, symptoms, and preventive measures to address cancer. Studies have recommended reducing tobacco use, increasing physical activity, controlling weight, improving diet, limiting alcohol consumption, conducting routine cancer screening tests, and avoiding excessive exposure to the sun to reduce cancer risks [30]. Unless perceived susceptibility is seriously considered, risky health-related behaviors may endure. Students in this study perceived several factors that increased the susceptibility of developing cancer. Therefore, if specific cues to action are introduced, adolescents have the potential to initiate healthy habits in society. These cues could be communicated through a message on a poster, calendar, playing cards, or a message reminder on any social media [31].

The government in Nepal has attempted to increase access to health care services to achieve high coverage. This study highlighted expensive medical services, ignorance and poverty, and a lack of strict rules and regulations as barriers to healthcare services. These findings are supported by another Nepali study that focused on inequality, poverty, traditional and cultural practices, and the heavy burden placed on healthcare professionals as the primary reason for poor health service quality [32]. Another Nepali study emphasized the unavailability of medicine at the health post hospitals while seeking healthcare services [33]. Barriers to health services and healthcare delivery require urgent intervention. Strengthening the health system and providing equitable distribution of health services 
must be endured by improving the efficiency of the hospital, monitoring unaffordable payments, motivating health workers, and building beneficial packages to cover major health services, including non-communicable diseases [34].

The study participants explored their understanding of cancer in their surroundings. The findings from the photovoice are related to practice, research, and education. It helped the participants identify health priorities and existing social problems around them. Decision-making on expenditure to healthcare heavily depends on the individual's health status and the certainty about the future [35]. It is more challenging to people in the low-income countries where people have to pay high cost from their pockets for the basic treatment without any health insurance support. Therefore, photovoices can be more effective in the context of low-resource setting where early detection of health problems can help to lower the burden of diseases on people [36]. Photovoices as a learning process can be considered a valuable tool for behavioural change interventions, focusing on identifying problems in society and providing a platform for unheard voices. Therefore, linking behavioural change techniques with CBPR can help to sustain behavioral change at the community level [20,37].

Various studies have suggested the need for schools to understand school community participation, its importance, and execution [38,39]. School-based health promotion interventions can include the photovoice method for health education and can address various public health-related issues in school and community-based settings. Application of the photovoice method within a school setting can help schools achieve healthy promoting environments more efficiently [40]. Within the classroom setting, teachers can flip the role of expert to being a facilitator and stimulate critical thinking of students and empower student's participation. Schools and communities must work together to foster capacity-building among students regarding their communities.

Visual methods are increasingly used in different disciplines. Visual methodologies are used to understand and interpret images, which includes photography, film, video, drawing, sculpture, artwork, graffiti, and cartoons. These methodologies are a new approach to qualitative research that have added another dimension to pre-existing methods by creating knowledge, which is becoming popular and beneficial in health and illness research [41]. Pictures closely linked to written text can effectively increase attention to and recall health education information more effectively than text alone [42]. In particular, people with low literacy skills are likely to benefit, and it is even easier to attract children and adolescents who are more likely to choose pictures over text. However, the promise of a photovoice as a robust visual research methodology and pedagogy lies in the rigor, trustworthiness, and adaptation of the project design and process [43].

Adolescents have a sense of self-worth and self-esteem, and thus have the confidence to express their views and act as change agents in the community [44]. The researcher played a process-facilitating role while participants engaged in the research process. Through this study, we can understand the perceptions and knowledge of adolescents regarding their surroundings, communication with each other, critical thinking, and problem-solving skills. This study suggests that adolescents should be involved in the planning, monitoring, and evaluation of health services and in decisions regarding their care. Moreover, photovoices can serve as a method for achieving results by empowering adolescents themselves to be change agents.

This study has several strength and limitations. This study involved students in the research process, which provided an opportunity to understand their concerns regarding cancer in their surroundings. The sharing of ideas and discussions among students increased their engagement in critical thinking, which helped them to achieve a deeper understanding and create a sense of responsibility toward their communities. However, the photovoice method requires time, effort, and commitment from the study participants. In addition, training sessions and group meetings must be conducted prior to actions to discuss and broaden the concept of learning. The researcher serves as a facilitator by 
supporting and guiding the data collection process; therefore, the findings may sometimes deviate from what the researchers intended to measure.

\section{Conclusions}

This study supports the adoption of a photovoice as a method for identifying cancer perception among high school students. The photovoice provided an opportunity for students to engage in the research process and explore their surroundings and discuss their perceptions of cancer in their areas. Students identified several barriers to health services, including gaps in laws and regulations. A deeper understanding of the learning process created a genuine and sustainable learning experience for participants. Incorporating a photovoice in the design, implementation, and monitoring can help address several unanswered questions. In addition, using a photovoice in collaboration with family members, community-based clubs, and local organizations can increase community engagement and allows for more empowered and sustainable actions. Further extensive studies are crucial for evaluating the long-term impact of photovoice on individual or community health.

Author Contributions: Conceptualization, K.P. and N.S.; methodology, K.P. and N.S.; validation, K.P. and N.S.; formal analysis, K.P.; investigation, K.P.; resources, N.S.; data curation, K.P.; writingoriginal draft preparation, K.P.; writing - review and editing, K.P. and N.S.; visualization, K.P. and N.S.; supervision, N.S.; project administration, K.P.; funding acquisition, N.S. All authors have read and agreed to the published version of the manuscript.

Funding: This research was funded by Japan Society for the Promotion of Science JSPS KAKENHI (Grant Number 18K1060008).

Institutional Review Board Statement: The study was conducted in accordance with the guidelines of the Declaration of Helsinki and approved by the Institutional Review Board of Hokkaido University, Japan, and the Nepal Health Research Council (2805).

Informed Consent Statement: Written consent was obtained from all participants prior to data collection. Informed consent was also obtained from the parents or guardians of the participants since they were under 18 years of age.

Data Availability Statement: The data are not publicly available due to ethical restrictions and specific legal framework in Japan. All inquiries should be addressed to Naomi Sumi, corresponding author of this paper.

Acknowledgments: We extend our sincere thanks to the students who participated in this study including their parents/guardians, and teachers who supported students throughout this study. We would like to appreciate Krishnaa Poudel for her efforts in contacting and collaborating school principals and teachers during data collection.

Conflicts of Interest: The authors declare no conflict of interest.

\section{References}

1. Pokharel, G. Reaching adolescents with health services in Nepal. Bull. World Health Organ. 2017, 95, 90-91. [CrossRef]

2. Global Accelerated Action for the Health of Adolescents (AA-HA!): Guidance to Support Country Implementation. Annexes 1-6 and Appendices I-IV; World Health Organization: Geneva, Switzerland, 2017.

3. Nepal Census. Central Bureau of Statistics, Government of Nepal. Available online: https://censusnepal.cbs.gov.np/Home/ Index/EN (accessed on 1 May 2021).

4. World Health Organization. Adolescents: Health Risks and Solutions. 2018. Available online: https://www.who.int/newsroom/fact-sheets/detail/adolescents-health-risks-and-solutions (accessed on 1 May 2021).

5. World Health Organization. Adolescent Health. Available online: https://www.who.int/health-topics/adolescent-health/\#tab=tab_2 (accessed on 1 May 2021).

6. Napit, K.; Shrestha, K.B.; Magar, S.A.; Paudel, R.; Thapa, B.; Dhakal, B.R.; Amatya, A. Factors associated with utilization of adolescent-friendly services in Bhaktapur district, Nepal. J. Health Popul. Nutr. 2020, 39, 1-9. [CrossRef]

7. Pandey, P.L.; Seale, H.; Razee, H. Exploring the factors impacting on access and acceptance of sexual and re-productive health services provided by adolescent-friendly health services in Nepal. PLOS ONE 2019, 14, e0220855. [CrossRef]

8. Thapa, B.; Powell, J.; Yi, J.; McGee, J.; Landis, J.; Rein, L.; Kim, S.; Shrestha, S.; Karmacharya, B. Adolescent Health Risk and Behavior Survey: A School Based Survey in Central Nepal. Kathmandu Univ. Med. J. 2017, 15, 301-307. 
9. Kyle, R.G.; Nicoll, A.; Forbat, L.; Hubbard, G. Adolescents' awareness of cancer risk factors and associations with health-related behaviors. Health Educ. Res. 2013, 28, 816-827. [CrossRef]

10. Poudel, K.; Sumi, N.; Yano, R. Impact of Peer-Led Cancer Education Program on Knowledge, Health Beliefs, Practice, and Self-Esteem Among Pairs of Nepalese High-School Students and Their Knowledge-Sharing Partners. Healthcare 2021, 9, 64. [CrossRef]

11. Parijs, L.G.V. Public education in cancer prevention. Bull. World Health Organ. 1986, 64, 912-927.

12. Malseed, C.; Nelson, A.; Ware, R. Evaluation of a School-Based Health Education Program for Urban Indigenous Young People in Australia. Health 2014, 6, 587-597. [CrossRef]

13. Abdi, F.; Simbar, M. The Peer Education Approach in Adolescents- Narrative Review Article. Iran. J. Public Health 2013, 42, 1200-1206.

14. Sharma, B.; Kim, H.Y.; Nam, E.W. Effects of School-based Health Promotion Intervention on Health Be-haviors among School Adolescents in North Lima and Callao, Peru. J. Lifestyle Med. 2018, 8, 60-71. [CrossRef]

15. Janz, N.K.; Becker, M.H. The Health Belief Model: A Decade Later. Health Educ. Q. 1984, 11, 1-47. [CrossRef]

16. Rosenstock, I.M. The Health Belief Model and Preventive Health Behavior. Health Educ. Monogr. 1974, 2, 354-386. [CrossRef]

17. Wang, C.; Burris, M.A. Photovoice: Concept, Methodology, and Use for Participatory Needs Assessment. Health Educ. Behav. 1997, 24, 369-387. [CrossRef]

18. Park, J.S.; Han, J.-W.; Choi, J.H.; Lee, K.C. Photovoice-Based Assessment of Weight Management Experiences of Breast Cancer Patients Treated with Tamoxifen. Int. J. Environ. Res. Public Health 2020, 17, 4359. [CrossRef]

19. Mmari, K.; Marshall, B.; Hsu, T.; Shon, J.W.; Eguavoen, A. A mixed methods study to examine the influence of the neighborhood social context on adolescent health service utilization. BMC Health Serv. Res. 2016, 16, 433. [CrossRef]

20. Nyambe, S.; Yamauchi, T. Peri-urban water, sanitation and hygiene in Lusaska, Zambia: Photovoice empowering local assessment via ecological theory. Glob. Health Promot. 2021, 1-11. [CrossRef]

21. Schell, K.; Ferguson, A.; Hamoline, R.; Shea, J.; Thomas, M.R. Photovoice as a teaching tool: Learning by doing with visual methods. Int. J. Teach. Learn. High. Educ. 2009, 21, 340-352.

22. Stroud, M. Research and Teaching: Photovoice as a Pedagogical Tool: Student Engagement in Undergraduate Introductory Chemistry for Nonscience Majors. J. Coll. Sci. Teach. 2014, 43, 98-107. [CrossRef]

23. Ciolan, L.; Manasia, L. Reframing Photovoice to Boost Its Potential for Learning Research. Int. J. Qual. Methods 2017, 16, 1609406917702909. [CrossRef]

24. Amos, S.; Read, K.; Cobb, M.; Pabani, N. Facilitating a photovoice project: What you need to know. In The Nova Scotia Participatory Food Costing Project; FoodARC: Halifax, Nova Scotia, 2012.

25. Wang, C.C.; Yi, W.K.; Tao, Z.W.; Carovano, K. Photovoice as a Participatory Health Promotion Strategy. Health Promot. Int. 1998, 13, 75-86. [CrossRef]

26. Wye, S.Q.; Madden, A.; Poeder, F.; McGuckin, S.; Shying, K. A Framework for Peer Education by Drug-User Organizations, Australia; Australian Injecting \& Illicit Drug Users League: Canberra, Australia, 2006.

27. Tomé, G.; Matos, M.; Simões, C.; Diniz, J.A.; Camacho, I. How can peer group influence the behavior of adoles-cents: Explanatory model. Glob. J. Health Sci. 2012, 4, 26-35. [CrossRef]

28. Streng, J.M.; Rhodes, S.D.; Ayala, G.X.; Eng, E.; Arceo, R.; Phipps, S. Realidad Latina: Latino adolescents, their school, and a university use photovoice to examine and address the influence of immigration. J. Interprof. Care 2004, 18, 403-415. [CrossRef]

29. Wilson, N.; Minkler, M.; Dasho, S.; Wallerstein, N.; Martin, A.C. Getting to social action: The youth empower-ment strategies (YES!) project. Health Promot. Pract. 2006, 14, 201-217.

30. Stein, C.J.; Colditz, G. Modifiable risk factors for cancer. Br. J. Cancer 2004, 90, 299-303. [CrossRef]

31. Lennon, J.L. The use of the health belief model in dengue health education. Dengue Bull. 2005, 29, $217-220$.

32. Bogren, M.; Erlandsson, K.; Johansson, A.; Kalid, M.; Igal, A.A.; Mohamed, J.; Said, F.; Pedersen, C.; Byrskog, U.; Osman, F. Health workforce perspectives of barriers inhibiting the provision of quality care in Nepal and So-malia- A qualitative study. Sex. Reprod. Healthc. 2020, 23, 100481. [CrossRef]

33. Paudel, R.; Upadhyaya, T.; Pahari, D.P. People's perspective on access to health care services in a rural district of Nepal. J. Nepal Med. Assoc. 2012, 52, 20-24. [CrossRef]

34. Mishra, S.R.; Khanal, P.; Karki, D.K.; Kallestrup, P.; Enemark, U. National health insurance policy in Nepal: Challenges for implementation. Glob. Health Action 2015, 8, 28763. [CrossRef]

35. Vuong, Q.H.; Ho, T.M.; Nguyen, H.K.; Vuong, T.T. Healthcare consumer's sensitivity to costs: A reflection on be-havioral economics from an emerging market. Palgrave Commun. 2018, 4, 70. [CrossRef]

36. Vuong, Q.H. Be rich or don't be sick: Estimating Vietnamese patient's risk of falling into destitution. Springerplus 2015, 4, 529. [CrossRef]

37. Bisung, E.; Elliott, S.J.; Abudho, B.; Karanja, D.M.; Wallace, C.S. Using Photovoice as a Community Based Participatory Research Tool for Changing Water, Sanitation, and Hygiene Behaviours in Usoma, Kenya. BioMed Res. Int. 2015, 2015, 903025. [CrossRef]

38. Kwatubana, S. School Community Participation and School Health Promotion: Challenges and Opportunities. Mediterr. J. Soc. Sci. 2014, 5, 1458. [CrossRef]

39. Aref, A. Community participation for educational planning and development. Nat. Sci. 2010, 8, 1-4. 
40. Warne, M.; Snyder, K.; Gadin, K.G. Photovoice: An opportunity and challenge for student's genuine participation. Health Promot. Int. 2012, 28, 299-310. [CrossRef] [PubMed]

41. Glaw, X.; Inder, K.; Kable, A.; Hazelton, M. Visual methodologies in qualitative research: Autophotography and photo elicitation applied to mental health research. Int. J. Qual. Methods 2017, 16, 1609406917748215. [CrossRef]

42. Houts, P.S.; Doak, C.C.; Doak, L.G.; Loscalzo, M.J. The role of pictures in improving health communication: A review of research on attention, comprehension, recall, and adherence. Patient Educ. Couns. 2006, 61, 173-190. [CrossRef]

43. Wang, T. Using photovoice as methodology, pedagogy and assessment tool in education: Graduate student's experiences and reflections. Beijing Int. Rev. Educ. 2020, 2, 112-135. [CrossRef]

44. UNICEF. Engaged and Heard! Guidelines on Adolescent Participation and Civic Engagement. Available online: https: //www.unicef.org/documents/engaged-and-heard-guidelines-adolescent-participation-and-civic-engagement (accessed on 5 May 2021). 